"This is the peer reviewed version of the following article: [Journal of Clinical Nursing]. which has been published in final form at

[https://onlinelibrary.wiley.com/doi/abs/10.1111/jocn.13838]. This article may be used for non-commercial purposes in accordance with Wiley Terms and Conditions for Self-

Archiving." 
DR. NICOLE BLAY (Orcid ID : 0000-0001-8515-4209)

DR. MICHAEL ANTHONY ROCHE (Orcid ID : 0000-0002-3831-537X)

PROF. ROBYN GALLAGHER (Orcid ID : 0000-0001-5588-9351)

Article type : Original Article

Title: Intra-hospital transfers and the Impact on Nursing Workload

Concise title: Patient transfers and nursing workload

Authors: Nicole BLAY; PhD, BHA, RN; formerly project manager Centre for Health Services Management, Faculty of Health, University of Technology Sydney \& Adjunct Fellow Western Sydney University. CHSM, Faculty of Health, UTS, PO Box 123, Broadway, NSW 2007.

T:+61412699111; Nicole.Blay@uts.edu.au

Michael ROCHE; PhD, RN; Associate Professor in Mental Health, Drug and Alcohol Nursing Northern Sydney Local Health District \& School of Nursing, Midwifery \& Paramedicine, Australian Catholic University. T: +61 (0)2 8877 5157; Michael.Roche@ acu.edu.au

Christine DUFFIELD; PhD, RN; Director, Centre for Health Services Management UTS, Faculty of Health, University of Technology Sydney \& Professor of Nursing and Health Services Management, Edith Cowen University; Contact: CHSM, Faculty of Health, UTS, PO Box 123, Broadway, NSW 2007. T: +61 29514 4831; Christine.Duffield@uts.edu.au Robyn GALLAGHER; PhD, RN: Professor of Nursing, Charles Perkins Centre, Sydney Nursing School, University of Sydney; NSW 2006. T +61 286270279 ; robyn.gallagher@sydney.edu.au

This article has been accepted for publication and undergone full peer review but has not been through the copyediting, typesetting, pagination and proofreading process, which may lead to differences between this version and the Version of Record. Please cite this article as doi: 10.1111 jocn. 13838

This article is protected by copyright. All rights reserved. 
Funding

No funding is associated with this manuscript

Acknowledgments

Sincere appreciation is extended to the nurses who participated in this study

\section{Intra-hospital Transfers and the Impact on Nursing Workload}

\section{ABSTRACT}

Aims and Objectives: To determine the rate of patient moves and the impact on nurses' time.

Background: Bed shortages and strategies designed to increase patient flow have led to a global increase in patient transfers between wards. The impact of transferring patients between wards and between beds within a ward on nurses' workload has not previously been measured. Design: A twostage sequential study. Retrospective analysis of hospital data and a prospective observationaltiming study Methods: Secondary analysis of an administrative dataset to inform the rate of ward and bed transfers ( $n=34,715)$ was undertaken followed by an observational-timing study of nurses' activities associated with patient transfers $(n=75)$. Results: Over 10,000 patients were moved 34,715 times in one year which equates to an average of .2.4 transfers per patient. On average, patient transfers took 42 minutes and bed transfers took 11 minutes of nurses' time. Based on the frequency of patient moves, 11.3 Full-time Equivalent nurses are needed to move patients within the site hospital each month. Conclusion: Transferring patients is workload intensive on nurses' time and should be included in nursing workload measurement systems. Relevance to Clinical Practice: Nurses at the site hospital spend over 1700 hours each month on activities associated with transferring patients, meaning that less time is available for nursing care.

Keywords: intra-hospital transfer, nursing activities, nurse workload, observational-timing study, secondary analysis, transfer.

This article is protected by copyright. All rights reserved. 


\section{What does this paper contribute to the wider global clinical community?}

- Transferring patients within the hospital system has implications for patient safety, continuity of care and nursing workload.

- To transfer a patient and relocate another within a ward to accommodate this patient, requires 54 minutes of nurses' time which could be spent on more value-added nursing care activities.

- Registered nurses are attending to transfer-associated tasks that could be delegated to other healthcare personnel.

\section{BACKGROUND}

Demand for healthcare services is increasing. In Australia as elsewhere, a high patient turnover associated with Emergency Department (ED) presentations, shorter hospital lengths of stay, the ageing population and increasing rates of chronic disease (ABS, 2012; AlHW, 2013, 2014) have added to nurses' workload pressures and demands on their time (Baernholdt, Cox, \& Scully, 2010; Myny et al., 2012). Despite the increased demands for care, the number of public hospital beds per 1,000 Australian population has declined by $0.9 \%$ per since $2008 / 2009$ (AlHW, 2014) meaning that more patients need to be accommodated in fewer hospital beds. Consequently, many hospitals operate at full capacity with occupancy levels of $90 \%$ (AMA, 2013) which many argue are inefficient, unsafe for patients and increase staff workload (AMA, 2008; Kaier, Mutters, \& Frank, 2012; Keegan, 2010; Weissman et al., 2007). In response to increased levels of throughput, hospitals have introduced a range of bed management strategies such as short-stay units and discharge lounges, designed to keep patients out of traditional hospital beds and increase patient flow (N. Blay, Duffield, \& Gallagher, 2012). An unfortunate consequence of some of these strategies is that they have

This article is protected by copyright. All rights reserved. 
contributed to increased 'patient churn' (Duffield, Diers, Aisbett, \& Roche, 2009) or 'the inflow and outflow of patient admissions, discharges and transfers' (R. G. Hughes, Bobay, Jolly, \& Suby, 2015) at ward and unit level.

A significant contributing factor to increased patient movements in hospitals in Australia is the introduction of the National Emergency Access Target (NEAT). The NEAT, similar to the U.K.'s Four Hour Rule, is designed to improve patient safety and increase patient flow (G. Hughes, 2010) by limiting the time that admitted patients can spend in the ED to four hours after which time they must be admitted, transferred to another hospital or discharged (Crawford et al., 2014; Weber, Mason, Carter, \& Hew, 2011). Unintended consequences of targets such as NEAT, bed shortages and short-stay units, is that patients are frequently nursed in any bed available (Bakes, 2014; N. Blay, et al., 2012; Corbally, Macri, \& Hawkshaw, 2014; Perera et al., 2016) only to be transferred at a later time when a more suitable bed becomes available (N. Blay, et al., 2012; West, 2010b). This results in hot-bedding, defined as the rapid turnover of patients per bedspace (N Blay, Duffield, Gallagher, \& Roche, 2014; Duffield, Diers, et al., 2009) and the need to move pre-existing patients from one bed to another in the same ward (defined here as a bed transfer) (N Blay, et al., 2014).

Researchers and nurse managers have begun to recognise that patient transfers need to be considered when calculating staffing requirements (Baernholdt, et al., 2010; R. G. Hughes, et al., 2015; Twigg, Duffield, Bremner, Rapley, \& Finn, 2011; Unruh \& Fottler, 2006). Many nursing workload measures rely on the midnight census to determine the number of patients in a clinical unit requiring nursing care (Baernholdt, et al., 2010; Beswick, Hill, \& Anderson, 2010; R. G. Hughes, et al., 2015; Simon, Yankovskyy, Klaus, Gajewski, \& Dunton, 2011). As a consequence nursing work associated with ward and bed transfers during the one day are not taken into account (N. Blay, et al., 2012; R. G. Hughes, et al., 2015). As the frequency of ward and bed transfers has not been determined, the time spent by nurses attending to this activity remains largely speculative ( $\mathrm{N}$ Blay,

This article is protected by copyright. All rights reserved. 
et al., 2014; R. G. Hughes, et al., 2015). This study sought to determine transfer rates between and within wards (or units), the clinical locations associated with such moves and the time spent by nurses moving patients to provide a more accurate measure for nurse staffing needs.

\section{Method}

\section{Design}

The study was completed in two sequential stages. In Stage 1, hospital administrative data were retrospectively examined to determine the rate and destination of intra-hospital transfers over the 2008/2009 financial year. Results from Stage 1 were essential for the second prospective stage of the study where these data identified the wards with high rates of ward and/or bed transfers. Stage 2 incorporated an observational-timing study from June to August 2013 to count and time activities performed by medical-surgical nurses when transferring patients. (Figure 1).

\section{Setting}

The study was conducted in a 500 bed public acute-care tertiary referral hospital in Sydney, Australia. One medical and one surgical ward with a high rate of patient transfers were used for the observational-timing study.

\section{Sample}

In Stage 1, administrative data pertaining to adult patients admitted to hospital with a length of stay (LOS) of at least 48 hours $(n=10,733)$. Patients whose LOS was less than 48 hours were excluded $(n=7433)$ as it was considered that such patients would likely be admitted to and discharged from a short-stay unit (Eijsvoogel et al., 2014).

Preliminary analyses determined that $98.4 \%$ of patients experienced 12 or fewer transfers per episode of care (range 1-132); therefore episodes of care with 13 or more transfers were considered outliers and excluded. Temporary transfers whereby the patient returns to the same ward following

This article is protected by copyright. All rights reserved. 
(for example) a diagnostic test were also excluded because hospital information systems are only able to record transfers to specific locations (Stevenson et al., 2011; West, 2010a).

Stage 2, explored 75 patient transfers conducted by nurses $(n=39)$ of all designations, working within one medical and one surgical ward.

\section{Procedure, Instruments \& Data Elements}

Human Research Ethics Committee (HREC) approval was granted from the relevant Health District (HREC/09/xxx/174 and 12/268(LNR/12/xxx/500) (identifying names withheld) and the University (2010-012 and 12/268). Approval included access to de-identified patient datasets and permission to observe and time consenting nursing staff in the clinical setting. Participation was voluntary, free from coercion and no enticement was offered. With the exception of designation, no personal nurse or patient data were collected.

\section{Stage 1}

Retrospective administrative data were obtained from the following databases: inPatient Management (iPM) and Admission, Transfer Separation (ATS). These provided patient demographic data and hospital and ward descriptive data that were used to determine the frequency that patients were moved between and within wards.

\section{Stage 2}

An observational-timing study was conducted. Nursing activities associated with patient transfers were observed and timed between 0800 and $1700 \mathrm{hrs}$ on weekdays, as data from Stage 1 demonstrated that this was the peak time and period for patient transfers. A total of 118 hours of observations were undertaken by a single observer in randomised blocks of time ranging from 2-6 hours over a seven week period.

This article is protected by copyright. All rights reserved. 
Ward transfers were considered to consist of two sequential types based on the nurses' role in the process. Nursing work associated with sending a patient to another location was considered a sending transfer and nursing work associated with receiving a patient, a receiving transfer. For sending transfers, the timing process commenced following confirmation of an available bed and once the nurse had been informed of the transfer. Timing continued until the patient departed the ward and (if applicable) the sending nurse had returned to the sending ward. For receiving transfers, timing commenced when the receiving nurse started preparation for the patient's arrival and/or took responsibility for the patient's care. Timing continued until the patient had been orientated to the new surroundings or until such time that the receiving nurse indicated that the transfer activities had concluded. Bed transfers were timed from the point that the move had been confirmed until the patient had been relocated and nursing handover had been completed (if applicable). Activities performed by other healthcare workers were not observed or timed.

A purpose-designed data collection tool, the Transfer Timing Tool (TTT) was used to observe and time nurses' activities when attending to ward and bed transfers. The TTT included 30 (15 activities for sending transfers and 15 for receiving transfers) identified from the published literature, hospital policies and/or role descriptions $(n=27)$ and during a pilot study $(n=3)$. Based on previous work sampling and timing studies (Ballermann, Shaw, Mayes, Gibney, \& Westbrook, 2011; Duffield \& Wise, 2003; Westbrook, Duffield, Li, \& Creswick, 2011), the listed activities were divided into six categories (Administration, Communication, Direct care, Documentation, Indirect care and Other) (refer to Table 1) to facilitate location on the TTT (Douglas et al., 2013).

\section{Analyses}

In Stage 1, ward and bed transfer rates were calculated for all wards/units at the site hospital from the administrative dataset. Ward transfers were calculated following a change in ward/unit ID and

This article is protected by copyright. All rights reserved. 
bed transfers were calculated following a change in the bedspace ID within the same ward. The results from Stage 1 were used to select two wards with a high rate of patient moves to be used as sites for Stage 2.

In Stage 2, nursing activities associated with sending and receiving transfers and bed transfers were observed and timed. All observed activities were timed from commencement to completion using an electronic timer running continuously. The time spent by nurses on each type of move and activity was calculated. Eight patient moves were excluded from analyses due to extended delays $(n=7)$ or the move did not fulfil study criteria $(n=1)$.

Analysis of Variance (ANOVA) was used to determine if there was a significant difference in the time taken to relocate a patient, the average and total time spent by nurses attending to patient transfers and the average number of nurses attending to each transfer as it is considered to be more robust compared to other tests (Gleason, 2013; McDonald, 2014). Tukey's HSD test was used for comparisons. All statistical analyses were performed at the 0.05 significance level.

\section{Results}

\section{Patient Transfers}

There were 10,733 patients with an average LOS of 9.1 days (median 5.9, SD 10.46). These patients experienced 34,715 moves within 14,157 episodes of care. The frequency of patient moves was such that in only $5.4 \%$ ( $n=766$ ) of episodes of care, the patient remained in the one location throughout their hospitalisation.

Patients were moved an average of 2.4 times (range 0-12, SD 1.78) spending an average of 3.4 days (median 5.9, SD 3.52) in each ward/unit and 2.8 days (median 2.1, SD 2.40) in each bedspace. The majority $(78.2 \%, n=27,142)$ of moves were transfers between wards and/or units with a further 21.8\% $(n=7573)$ being transfers between beds within the one ward.

This article is protected by copyright. All rights reserved. 
Patients were transferred to many different locations throughout their episode of care. Most frequently patients were transferred to the medical-surgical and high intensity nursing units. Bed transfers were prevalent within the medical-surgical, aged care and rehabilitation wards (Table 2). Based on the high rate of ward and bed transfers associated with the medical-surgical specialties $(n=12)$ further analyses were undertaken. In this hospital, staff on medical-surgical wards transferred 4504 patients to other locations and received a further 12,166 patients in one year. This equates to an average of 1389 transfers per month.

\section{Transfers and Nursing Time}

Nurses on the medical and surgical units were observed and timed transferring patients $(n=75)$ as shown in Table 3. Results determined that relocating a patient averaged 57.5 minutes from the time that the transfer was confirmed to the time that the transfer was completed (range 5.2-235.6, SD 50.09). Sending transfers averaged 61.6 minutes (range 5.3-235, SD 61.07) receiving transfers 68.3 minutes (range 19.7-186.2, SD 49.16) and bed transfers 29.2 minutes (range 5.2-67.4, SD 21.13) (Table 4). Receiving transfers took significantly longer than bed transfers (Tukey's HSD $p=.020$ ).

The nurse spent less time directly attending to the patient move compared to the move duration. Sending transfers averaged 17.7 minutes of nurses' time, receiving transfers 24.6 minutes, and bed transfers 11.3 minutes (Table 4). Therefore, to send and receive an individual patient and relocate one other (bed transfer) took an accumulated 53.6 minutes of nursing time.

The time spent by nurses by the type of move was significant $(p=.017)$ (Table 4). Post-hoc analyses showed that nurses spent significantly more time on receiving transfers than bed transfers $(p=$ .015). In terms of the time spent attending to patient transfers by specialty, nurses working on the medical units spent an average of 21.0 minutes and surgical unit nurses 18.0 minutes. This difference in time was not significant.

This article is protected by copyright. All rights reserved. 
A significant difference in the number of nurses attending to each type of transfer was noted ( $p$ $=.024)$. On average 2.0 nurses assisted with each transfer (range 1-4, SD 0.80). Bed transfers required 2.4 nurses compared to 1.7 and 1.9 nurses for sending or receiving transfers respectively (Table 4). Post-hoc analyses confirmed that the differences lie between the mean number of nurses attending to sending transfers and bed transfers $(p=.020)$. However, the number of nurses assisting with each patient move did not have a significant impact on the time taken to transfer a patient $(p=$ $.612)$.

Based on the frequency of patient transfers and the time spent by nurses on each type of transfer (sending or receiving transfer and bed transfer) it was calculated that nurses at the site hospital spend 1713.4 hours (71.4 days) each month relocating patients. Converting the time spent by nurses on transfer related activities into Full-time Equivalents (FTE) more fully demonstrates the impact on nurses' workload. Based on a 38 hour week as worked by nurses in Australia and using standard formula (Government of Western Australia, n.d.) it was calculated that 11.3 nurses are needed to transfer patients in the site hospital each month. For medical-surgical wards alone, the 600.1 hours (25 days) spent each month transferring patients equates to 3.9 FTE nurses.

\section{Discussion}

This study has used secondary data to explore the frequency that patients are transferred and an observational-timing study to determine the time taken to transfer patients. Results from this study support previous findings that transferring a patient can take approximately one hour (Hendrich \& Lee, 2005; Kibler \& Lee, 2011) although there is also much variability (Jennings, Sandelowski, \& Higgins, 2013) with some transfers taking less than ten minutes and others taking several hours. Considering the shortage of hospital beds and that the need to transfer a patient can lead to a succession of bed transfers ( $\mathrm{N}$ Blay, et al., 2014), the time required to move patients has major implications for bed availability, Emergency Department targets and nurses' workload.

This article is protected by copyright. All rights reserved. 
The study supports the claim that patient transfers are nursing workload intensive (Hendrich \& Lee, 2005) and disruptive to workflow (Jennings, et al., 2013). The amount of nursing time to transfer one patient was 42 minutes which is considerably longer than previously reported (N Blay, et al., 2014). Furthermore, to transfer one patient frequently means that other patients may need to be relocated within the ward or unit, adding at least 11 minutes to the entire process. The impact on nurses' workload and workflow is substantial considering that the entire process requires two (or more) nurses and that the remaining nurses must care for patients already on the unit (Duffield, Roche, O'Brien-Pallas, \& Catling-Paull, 2009; Jennings, et al., 2013).

The impact on nursing workload of transferring a patient is most clearly realised when the rate of medical-surgical transfers is taken into account. At the site hospital, almost 3000 patient moves took place each month taking 1700 hours of nursing time. For medical-surgical nurses alone, relocating an average of 1780 patients per month required 600 hours of nursing time. Based on the nursing time required, the equivalent of 71 days each month is spent by nurses relocating patients within and between units in the site hospital. The impact on nurses' workload is more aptly demonstrated when the time spent is converted to FTE positions. Based on a 38 hour working week, 11 FTE nurses were required each month to move patients in this 500 bed hospital. Within the medical-surgical units alone, 4 FTE nurses were required each month. The need for four full-time nurses to move and transfer medical-surgical patients, in addition to other nursing activities, goes some way to explain why patient turnover has a major influence on nursing workload and workflow (Duffield, Diers, et al., 2009; Jennings, et al., 2013; Myny, et al., 2012).

The fact that the ratio of nurses made little difference to the time taken to relocate the patient is surprising although patient characteristics could have been an influencing factor. Nurses experienced with the transfer process may well be aware that in some situations more than one nurse is needed to attend to the patient's needs. The pressure for beds might also influence the number of nurses who are needed to provide assistance with transferring a patient. Less nursing

This article is protected by copyright. All rights reserved. 
time was required for bed transfers compared to ward transfers, and yet, (paradoxically) bed transfers required two or more nurses. Moving the bed and bedside equipment from one bedspace to another necessitated several nurses because of the 'domino effect' of one move leading to several other moves. Nurses' time saved, coupled with reductions in the time taken to transfer patients to the unit, would more than offset the financial cost of employing additional orderlies, porters or nursing assistants to aid the bed transfer process (Farris, Matis, McAllister, \& Snider, 2010).

\section{Limitations}

A limitation of Stage 1 is the possibility that not all patient moves were captured. The number of transfers is potentially much higher than depicted as temporary transfers and short-stay patients were excluded. Both temporary transfers and short-stay patients are known to have an impact on nurses' time and workload (Griffiths, 2011; Park, Blegen, Spetz, Chapman, \& De Groot, 2012; Simon, et al., 2011; Webster, Davies, Stankiewicz, \& Fleming, 2011). Furthermore, the rate of patient transfers was calculated on 2008/2009 data. Considering that hospital presentations and bed shortages have continued to increase over time, it is likely that the number of ward and bed transfers is now greater than that predicted.

The transfer duration and the time spent by nurses attending to patient transfers may have been underestimated. Some activities may not have been observed and/or timed and some patient transfers were not observed in their entirety. Activities performed by non-nurses were not observed and/or recorded. Seven transfers were excluded due to extended delays. Excluding these transfers may have positively skewed the data.

This article is protected by copyright. All rights reserved. 


\section{Conclusion}

This is the first study to comprehensively examine bed and ward transfers over a one year period and to use that data to determine the impact on nursing workload. Results confirm that patients are moved more frequently than ever before within and between units during their hospital stay. The impact that this has for patient safety and nurses' workload is significant. Employing additional healthcare personnel to assist with some of the tasks associated with patient transfers would be a cost effective solution to reducing nursing workload while including the rate of ward and bed transfers in nursing workload measurement systems will more accurately inform for nurse staffing needs.

\section{Relevance to Clinical Practice}

This study has demonstrated that transferring patients is nursing workload intensive. Nursing workload measurement systems therefore need to take into account the rate of ward and bed transfers in order to more accurately reflect staffing needs. Furthermore, when it is considered that the majority of bed transfers required more than two nurses, the time that nurses spend away from value-added activities is substantial and may impact patient safety (Baernholdt, et al., 2010; Yakusheva, Lindrooth, \& Weiss, 2014).

\section{References}

ABS. (2012). Australian Demographic Statistics, June 2012 Population by Age and Sex, Australia, States and Territories. Canberra: Australian Bureau of Statistics.

AIHW. (2013). Australia's Health 2012: The thirteenth biennial health report of the Australian Institute of Health and Welfare. Canberra: Australian Institute of Health and Welfare Retrieved from http://www.aihw.gov.au/WorkArea/DownloadAsset.aspx?id=10737422169.

AIHW. (2014). Australian hospital statistics 2012-13. Canberra: Australian Institute of Health and Welfare Retrieved from http://www.aihw.gov.au/WorkArea/DownloadAsset.aspx?id=60129547000.

This article is protected by copyright. All rights reserved. 
AMA. (2008). Public Hospital Report Card 2008: an AMA analysis of Australia's public hospital system. Kingston, ACT: Australian Medical Association.

AMA. (2013). Public Hospital Report Card 2013: an AMA analysis of Australia's public hospital system. Barton, ACT: Australian Medical Association.

Baernholdt, M., Cox, K., \& Scully, K. (2010). Using clinical data to capture nurse workload: implications for staffing and safety. CIN: Computers, Informatics, Nursing, 28(4), 229-234. doi: 10.1097/NCN.0b013e3181e1e57d

Bakes, B. (2014). Acute outliers in rehabilitation beds: Is a bed a bed? [Guest editorial]. Journal of the Australasian Rehabilitation Nurses Association, 17(3), 3-6.

Ballermann, M. A., Shaw, N. T., Mayes, D. C., Gibney, R. T. N., \& Westbrook, J. I. (2011). Validation of the Work Observation Method By Activity Timing (WOMBAT) method of conducting time-motion observations in critical care settings: an observational study. BMC Medical Informatics and Decision making, 11(32), 1-12. Retrieved from http://www.biomedcentral.com.ezproxy.lib.uts.edu.au/content/pdf/1472-6947-11-32.pdf doi:10.1186/1472-6947-11-32

Beswick, S., Hill, P. D., \& Anderson, M. A. (2010). Comparison of nurse workload approaches. Journal of Nursing Management, 18(5), 592-598. doi: 10.1111/j.1365-2834.2010.01124.x

Blay, N., Duffield, C., \& Gallagher, R. (2012). Patient transfers in Australia: implications for nursing workload and patient outcomes. Journal of Nursing Management, 20(3), 302-310.

Blay, N., Duffield, C., Gallagher, R., \& Roche, M. (2014). A Systematic Review of Time Studies to Assess the Impact of Patient Transfers on Nurse Workload. International Journal of Nursing Practice, 20(6), 662-673. doi: 10.1111/ijn.12290

Corbally, M., Macri, G., \& Hawkshaw, S. (2014). An examination of the role and activities of nurses caring for patients who are admitted to a model 4 hospital as part of the National Acute Medicine Programme Final Report (pp. 95): Dublin City University

Crawford, K., Morphet, J., Jones, T., Innes, K., Griffiths, D., \& Williams, A. (2014). Initiatives to reduce overcrowding and access block in Australian emergency departments: A literature review. Collegian, 21(4), 359-366. doi: http://dx.doi.org/10.1016/j.colegn.2013.09.005

Douglas, S., Cartmill, R., Brown, R., Hoonakker, P., Slagle, J., Schultz Van Roy, K., . . Carayon, P. (2013). The work of adult and pediatric intensive care unit nurses. Nursing Research, 62(1), 50-58. doi: 10.1097/NNR.0b013e318270714b

Duffield, C., Diers, D., Aisbett, C., \& Roche, M. (2009). Churn: Patient Turnover And Case Mix. Nursing Economic\$, 27(3), 185-191.

Duffield, C., Roche, M., O'Brien-Pallas, L., \& Catling-Paull, C. (2009). The Implications of Staff 'Churn' for Nurse Managers, Staff and Patients. Nursing Economics, 27(3), 185-192.

Duffield, C., \& Wise, W. (2003). Tell me what we do: using work sampling to find the answer. Australian Journal of Advanced Nursing, 20(3), 19-23.

Eijsvoogel, C. F. H., Peters, R. W., Budding, A. J., Ubbink, D. T., Vermeulen, H., \& Schep, N. W. L.

This article is protected by copyright. All rights reserved. 
(2014). Implementation of an acute surgical admission ward. British Journal of Surgery, 101(11), 1434-1438. doi: 10.1002/bjs.9605

Farris, J. A., Matis, T. I., McAllister, M., \& Snider, A. (2010). Applying healthcare systems engineering methods to the patient discharge process. International Journal of Collaborative Enterprise, 1(3/4), 293-315.

Gleason, J. (2013). Comparative Power Of The Anova, Randomization Anova, And Kruskal-Wallis Test. Wayne State University Dissertations. Retrieved from http://digitalcommons.wayne.edu/oa_dissertations/658 (Paper 658)

Government of Western Australia. (n.d.). How NHpPD Can Be Used to Calculate Staffing for Your Ward / Unit, from http://www.nursing.health.wa.gov.au/docs/planning/NHpPD_calculating_staffing.pdf

Griffiths, P. (2011). A community of practice: the nurses' role on a medical assessment unit. [Article]. Journal of Clinical Nursing, 20(1/2), 247-254. doi: 10.1111/j.1365-2702.2009.03135.x

Hendrich, A., \& Lee, N. (2005). Intra-Unit Patient Transports: Time, Motion, and Cost Impact On Hospital Efficiency. Nursing Economics, 23(4), 157-164.

Hughes, G. (2010). Four hour target for EDs: The UK experience. Emergency Medicine Australasia, 22(5), 368-373. doi: 10.1111/j.1742-6723.2010.01326.x

Hughes, R. G., Bobay, K. L., Jolly, N. A., \& Suby, C. (2015). Comparison of nurse staffing based on changes in unit-level workload associated with patient churn. Journal of Nursing Management, 23(3), 390-400. doi: 10.1111/jonm.12147

Jennings, B. M., Sandelowski, M., \& Higgins, M. K. (2013). Turning over patient turnover: An ethnographic study of admissions, discharges, and transfers. Research in Nursing \& Health, 36(6), 554-566. doi: 10.1002/nur.21565

Kaier, K., Mutters, N. T., \& Frank, U. (2012). Bed occupancy rates and hospital-acquired infectionsshould beds be kept empty? Clinical Microbiology and Infection, 18(10), 941-945. doi: 10.1111/j.1469-0691.2012.03956.x

Keegan, A. D. (2010). Hospital bed occupancy: more than queuing for a bed. The Medical journal of Australia, 193(5), 291-293.

Kibler, J., \& Lee, M. (2011). Improving Patient Transfer between the Intensive Care Unit and the Medical/Surgical Floor of a 200-Bed Hospital in Southern California. Journal for Healthcare Quality, 33(1), 68-76. doi: 10.1111/j.1945-1474.2010.00101.x

McDonald, J. H. (2014). Handbook of Biological Statistics Retrieved from http://www.biostathandbook.com/kruskalwallis.html

Myny, D., Van Hecke, A., De Bacquer, D., Verhaeghe, S., Gobert, M., Defloor, T., \& Van Goubergen, D. (2012). Determining a set of measurable and relevant factors affecting nursing workload in the acute care hospital setting: A cross-sectional study. International Journal of Nursing Studies, 49(4), 427-436. doi: 10.1016/j.jijurstu.2011.10.005

Park, S. H., Blegen, M. A., Spetz, J., Chapman, S. A., \& De Groot, H. (2012). Patient turnover and the

This article is protected by copyright. All rights reserved. 
relationship between nurse staffing and patient outcomes. Research in Nursing \& Health, 35(3), 277-288. doi: 10.1002/nur.21474

Perera, M. L., Gnaneswaran, N., Roberts, M. J., Giles, M., Liew, D., Ritchie, P., \& Chan, S. T. F. (2016). The 'four-hour target' and the impact on Australian metropolitan acute surgical services. ANZ Journal of Surgery, 86(1-2), 74-78. doi: 10.1111/ans.13186

Simon, M., Yankovskyy, E., Klaus, S., Gajewski, B., \& Dunton, N. (2011). Midnight census revisited: Reliability of patient day measurements in US hospital units. International Journal of Nursing Studies, 48(1), 56-61. doi: 10.1016/j.ijnurstu.2010.07.002

Stevenson, J., Anderson, S., Veach, K., Hine, B.-A., Webster, J., Fleming, L., \& Osborne, S. (2011). Occupancy data: unravelling the mystery. Australian Journal of Advanced Nursing, 29(2), 512.

Twigg, D., Duffield, C., Bremner, A., Rapley, P., \& Finn, J. (2011). The impact of the nursing hours per patient day (NHPPD) staffing method on patient outcomes: A retrospective analysis of patient and staffing data. International Journal of Nursing Studies, 48(5), 540-548. doi: 10.1016/j.ijnurstu.2010.07.013

Unruh, L. Y., \& Fottler, M. D. (2006). Patient Turnover and Nursing Staff Adequacy. Health Services Research, 41(2), 599-612. doi: 10.1111/j.1475-6773.2005.00496.x

Weber, E. J., Mason, S., Carter, A., \& Hew, R. L. (2011). Emptying the Corridors of Shame: Organizational Lessons From England's 4-Hour Emergency Throughput Target. Annals of Emergency Medicine, 57(2), 79-88.e71. doi: 10.1016/j.annemergmed.2010.08.013

Webster, J., Davies, H., Stankiewicz, M., \& Fleming, L. C. (2011). Estimating the Time Involved in Managing the 'Unoccupied Bed:' A Time and Motion Study. Nursing Economics, 29(6), 317322. doi: 10.1186/1472-6963-9-110.

Weissman, J., S. , Rothschild, J., M. , Bendavid, E., Sprivulis, P., Cook, E. F., Evans, R. S., . . Bates, D. W. (2007). Hospital Workload and Adverse Events. Medical Care, 45(5), 448-455.

West, D. (2010a). Half of hospital trusts cannot report patient transfer data. Nursing Times.net. Retrieved from http://www.nursingtimes.net/specialist-news/infection-control-news/half-ofhospital-trusts-cannot-report-patient-transfer-data/5019996.article

West, D. (2010b). Hospital bed transfers put thousands of patients at risk of infection. Nursing times.net. Retrieved from http://www.nursingtimes.net/specialist-news/infection-controlnews/hospital-bed-transfers-put-thousands-of-patients-at-risk-of-infection/5019997.article

Westbrook, J. I., Duffield, C., Li, L., \& Creswick, N. J. (2011). How much time do nurses have for patients? a longitudinal study quantifying hospital nurses' patterns of task time distribution and interactions with health professionals. BMC Health Services Research, 11(319). Retrieved from http://www.biomedcentral.com/content/pdf/1472-6963-11-319.pdf doi:10.1186/1472-6963-11-319

Yakusheva, O., Lindrooth, R., \& Weiss, M. (2014). Nurse Value-Added and Patient Outcomes in Acute Care. Health Services Research, 49(6), 1767-1786. doi: 10.1111/1475-6773.12236

This article is protected by copyright. All rights reserved. 
Table 1: Identified Nursing Transfer Activities

\begin{tabular}{|c|c|c|}
\hline Category & Sending Transfer* & Receiving Transfer* \\
\hline \multirow[t]{7}{*}{ Administration } & Request wardsperson/porter. & \\
\hline & Redirect services e.g. diet, pharmacy. & \\
\hline & Compile medical record and charts. & Compile medical record and charts. \\
\hline & Coordinate environmental services. & \\
\hline & & Staffing/beds. \\
\hline & & Update iPM, admission-discharge book \\
\hline & & or unit board. \\
\hline \multirow[t]{5}{*}{ Communication } & Bed Management. & Bed Management. \\
\hline & Healthcare professionals. & Healthcare professionals. \\
\hline & Patient, family or carer. & Patient/family/carer. \\
\hline & Nursing handover (telephone). & Nursing handover (telephone). \\
\hline & & Nursing handover (face-face). \\
\hline \multirow[t]{4}{*}{ Direct care } & Patient preparation. & Settle and orientate patient. \\
\hline & Disconnect \& prepare equipment & Disconnect/reconnect equipment. \\
\hline & Perform vital signs, administer & Perform vital signs, administer \\
\hline & medications, dressings, procedures. & medications, dressings, procedures. \\
\hline
\end{tabular}

This article is protected by copyright. All rights reserved. 


\section{Nurse escort.}

Documentation Medical Record, Electronic Medical

Record (EMR), charts, care plan.

Indirect care

Pack patient belongings.

Move bedside table and locker.
Patient assessment.

Medical Record, EMR, charts, care plan.

Unpack patient belongings.

Move bedside table and locker.

Other

*Includes bed transfers

Table 2: Ward and Bed Transfers by Clinical Specialty

\begin{tabular}{|c|c|c|c|c|c|c|}
\hline \multirow[t]{2}{*}{ Specialty } & \multicolumn{2}{|c|}{ Ward transfers } & \multicolumn{2}{|c|}{ Bed transfers } & \multicolumn{2}{|l|}{ Total } \\
\hline & $\mathrm{n}$ & $\%$ & $\mathrm{n}$ & $\%$ & $\mathrm{n}$ & $\%$ \\
\hline Medical & 6379 & 23.5 & 2921 & 38.6 & 9300 & 26.8 \\
\hline Surgical & 5787 & 21.3 & 1774 & 23.4 & 7561 & 21.8 \\
\hline \multicolumn{7}{|l|}{ High nursing intensity } \\
\hline \multicolumn{7}{|l|}{ units* } \\
\hline Aged care/Rehabilitation & 2434 & 9.0 & 1333 & 17.6 & 3767 & 10.9 \\
\hline Assessment units & 3309 & 12.2 & 285 & 3.8 & 3594 & 10.4 \\
\hline \multicolumn{7}{|l|}{ Operating theatre \& } \\
\hline & 1664 & 6.1 & 1 & 0.0 & 1665 & 4.8 \\
\hline
\end{tabular}

This article is protected by copyright. All rights reserved. 


\begin{tabular}{|c|c|c|c|c|c|c|}
\hline Oncology & 1111 & 4.1 & 436 & 5.8 & 1547 & 4.5 \\
\hline Transit lounge & 1194 & 4.4 & 5 & 0.1 & 1199 & 3.5 \\
\hline ED/EMU** & 595 & 2.2 & 54 & 0.7 & 649 & 1.9 \\
\hline Dialysis & 488 & 1.8 & 0 & 0.0 & 488 & 1.4 \\
\hline Day only/Short-stay & 319 & 1.2 & 10 & 0.1 & 329 & 0.9 \\
\hline Paediatrics/Maternity & 43 & 0.2 & 7 & 0.1 & 50 & 0.1 \\
\hline Total & 27,142 & $100 \%$ & 7573 & $100 \%$ & 34715 & $100 \%$ \\
\hline
\end{tabular}

Abbreviations: ED, Emergency Department; EMU, Emergency Medical Unit.

*Includes Intensive Care Unit, Coronary Care Unit and High Dependency Unit.

**Excluded as admission units.

Table 3: Observed Transfers by Clinical Specialty

\begin{tabular}{|c|c|c|c|c|c|c|}
\hline & \multicolumn{2}{|c|}{ Sending transfers } & \multicolumn{2}{|c|}{ Receiving transfers } & \multicolumn{2}{|c|}{ Bed transfers } \\
\hline & $\mathbf{n}$ & $\%$ & $\mathrm{n}$ & $\%$ & $\mathrm{n}$ & $\%$ \\
\hline Medical $(n=39)$ & 16 & 21.3 & 14 & 18.7 & 9 & 12.0 \\
\hline Surgical $(n=36)$ & 6 & 8.0 & 22 & 29.3 & 8 & 10.7 \\
\hline Total & 22 & $29.3 \%$ & 36 & $48.0 \%$ & 17 & $22.7 \%$ \\
\hline
\end{tabular}

This article is protected by copyright. All rights reserved. 
Table 4: Duration, Nursing Time and the Number of Nurses Attending to Patient Transfers

\begin{tabular}{|c|c|c|c|c|c|c|c|c|}
\hline & \multirow{2}{*}{\multicolumn{2}{|c|}{$\begin{array}{l}\text { Sending } \\
\text { transfers }(n=22)\end{array}$}} & \multirow{2}{*}{\multicolumn{2}{|c|}{$\begin{array}{l}\text { Receiving } \\
\text { transfers ( } n=36 \text { ) }\end{array}$}} & \multirow{2}{*}{\multicolumn{2}{|c|}{$\begin{array}{l}\text { Bed transfers } \\
(n=17)\end{array}$}} & \multirow[b]{3}{*}{$\mathrm{F}(d f)^{* *}$} & \multirow[b]{3}{*}{$p$} \\
\hline & & & & & & & & \\
\hline & Mean & SD & Mean & SD & Mean & SD & & \\
\hline Transfer duration* & 61.6 & 60.07 & 68.3 & 49.16 & 29.2 & 21.13 & $3.92(2,72)$ & .024 \\
\hline Direct nursing time* & 17.7 & 14.59 & 24.6 & 16.91 & 11.3 & 15.01 & $4.30(2,72)$ & .017 \\
\hline Attending nurses (n) & 1.7 & 0.78 & 1.9 & 0.72 & 2.4 & 0.8 & $3.92(2,72)$ & .024 \\
\hline
\end{tabular}

Notes:

*Duration reported in minutes.

**ANOVA

This article is protected by copyright. All rights reserved. 


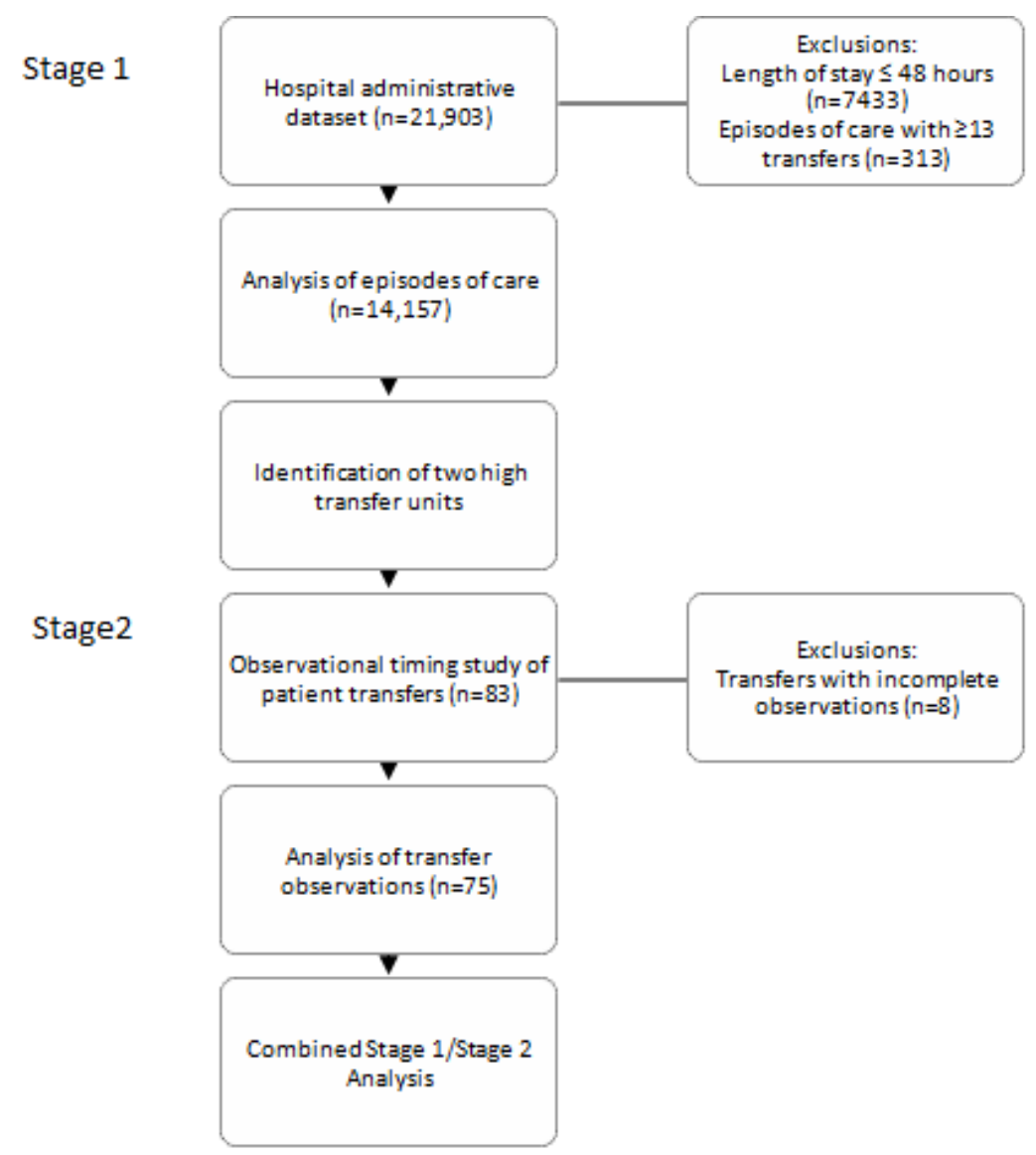

Figure 1: Flow chart method

This article is protected by copyright. All rights reserved. 